\title{
Developmental Changes in Endogenous Abscisic Acid Concentrations and Asymbiotic Seed Germination of a Terrestrial Orchid, Calanthe tricarinata Lindl.
}

\author{
Yung-I. Lee, Chia-Fu Lu, and Mei-Chu Chung ${ }^{1}$ \\ Institute of Plant and Microbial Biology, Academia Sinica, 115, Taipei, Taiwan, ROC \\ Edward C. Yeung \\ Department of Biological Science, University of Calgary, Calgary, Alberta T2N 1N4, Canada \\ Nean Lee \\ Department of Horticulture, National Taiwan University, No 1, Sec. 4, Roosevelt Road, 106, Taipei, \\ Taiwan, ROC

\begin{abstract}
AdDitional INDEX wORDs. cuticle, embryo development, enzyme-linked immunosorbent assay, seed pretreatment
ABstract. Changes in endogenous abscisic acid (ABA) concentrations were investigated in developing seeds and the pretreated seeds of Calanthe tricarinata, a hard-to-germinate terrestrial orchid. ABA concentration was as low as 2.16 to $2.26 \mathrm{ng} \cdot \mathrm{mg}^{-1}$ fresh weight at the proembryo stage [60 to 90 days after pollination (DAP)] and then continuously increased to $11.6 \mathrm{ng} \cdot \mathrm{mg}^{-1}$ fresh weight at $210 \mathrm{DAP}$. Seed maturation was accompanied by a dramatic decrease in water content and a prominent accumulation of protein and lipid bodies within the embryo proper. The optimum time for asymbiotic seed germination was obtained from immature seeds at 150 DAP. At this stage, the embryo proper reached its maximum size, and the seedcoat became dehydrated and gradually shrunk into a thin layer. By 180 DAP, seed germination declined sharply as seed approached maturity. Mature seeds pretreated with ultrasound (45 min), 1\% $\mathrm{NaOCl}$ (45 to $60 \mathrm{~min}$ ), or $1 \mathrm{~N} \mathrm{NaOH}(45 \mathrm{~min})$ were effective in improving the germination percentage and lowering seed ABA concentrations. Our results suggest that high concentrations of endogenous ABA in orchid seeds may play a critical role in arresting embryo growth and in preventing seed germination.
\end{abstract}

The flowers of Calanthe tricarinata, one of the most beautiful native terrestrial orchids in Taiwan, have deep-green sepals and petals with a scarlet labellum. This species has shown potential in the nursery trade and is used as a breeding stock. Plants currently sold by nursery growers mostly are collected from wild stands. Therefore, practical and efficient methods of propagation are necessary to prevent depletion of natural populations.

A capsule of orchids usually holds numerous tiny seeds after successful pollination events (Arditti, 1967). At the time of capsule maturation, the seed has a thin seedcoat and a globularshaped embryo without an endosperm. In the natural condition, the germination of orchid seeds is dependant on the formation of an association with the appropriate mycorrhizal fungi. Since Knudson's (1922) discovery that orchid seeds can germinate on a culture medium without mycorrhizal fungi, this method has been known as asymbiotic germination and has become a useful propagation technique for most orchids. Nevertheless, seeds of

Received for publication 25 Apr. 2006. Accepted for publication 28 Sept. 2006. We thank Mei-Fong high-land farm (National Taiwan University) for maintaining the plant materials. We also thank Professor Ching-Huei Kao and Professor Huu-Sheng Lur of the Department of Agronomy, National Taiwan University, for their advice and help on endogenous abscisic acid analysis.

This work was supported by grants from the Council of Agriculture of Taiwan to Nean Lee, from Academia Sinica, Taiwan, to Mei-Chu Chung, and from the Natural Sciences and Engineering Research Council of Canada to Edward C. Yeung.

${ }^{1}$ Corresponding author. E-mail: bomchung@gate.sinica.edu.tw. a few genera of terrestrial orchids are still considered difficult to germinate (Kano, 1968). The causes of low germination may relate to the impermeability of the seedcoat (Lee et al., 2005; Veyret, 1969) or the occurrence of substances inhibitory to germination (Van der Kinderen, 1987; Van Waes and Debergh, 1986a). Attempts were made to improve germination of terrestrial orchids by pretreating seeds with hypochlorite (Van Waes and Debergh, 1986a), ultrasound (Miyoshi and Mii, 1988), and chilling (Chu and Mudge, 1994; Shimura and Koda, 2005). However, it is not clear whether the improvement in seed germination after various pretreatments is the result of a reduction in the concentration of endogenous inhibitors. In a recent study, high concentration of endogenous abscisic acid (ABA) were found to accumulate in mature seeds of Cypripedium formosanum Hayata, and the exogenous ABA application also suppressed seed germination in vitro (Lee, 2003). We attempted to gain a better insight into the role of endogenous ABA in orchid seeds, and the relationship between ABA and various pretreatments before germination. The objectives of this study are to 1) document key anatomic features in embryo development, 2) investigate changes of endogenous ABA in developing seeds and mature seeds after pretreatments, and 3) compare the effects of pretreatments on seed germination in vitro.

\section{Materials and Methods}

Plant material and capsule collection. Plants of C. tricarinata were maintained in the greenhouses at Mei-Fong 
high-land farm (lat. 24.05' N, long. $121.11^{\prime} \mathrm{E}, 2100 \mathrm{~m}$ above sea level), Nantou, Taiwan. The greenhouses were shadowed with a black net to reduce the light intensity by $40 \%$. The plants successively flower from the end of March to early April. Thirty vigorous plants were selected for pollination. For this study, the flowers were labeled and hand-pollinated as soon as they opened; each of the plants had three capsules. Fertilization occurred $\approx 65 \mathrm{~d}$ after pollination (DAP). Capsules were sampled continuously every $30 \mathrm{~d}$ from May to October (60 to 210 DAP).

DETERMining WATER CONTENT OF DEVELOPING SEEDS. At each sampling stage, there were 20 replicates composed of seeds from those five capsules. Seeds were removed carefully from the placenta and then dried at $70^{\circ} \mathrm{C}$ for $48 \mathrm{~h}$. The water content was calculated as follows:

water content $(\%)=[($ fresh weight - dry weight $) /$ fresh weight $]$ $\times 100$.

Histologic PREParations. Developing seeds were collected and fixed in a solution of $2 \%$ paraformaldehyde and $2.5 \%$ glutaraldehyde in $0.1 \mathrm{M}$ sodium phosphate buffer, $\mathrm{pH} 6.8$, at $4{ }^{\circ} \mathrm{C}$ overnight. After fixation, the seeds were dehydrated through a methyl cellosolve (Sigma Chemical Co., St. Louis), $100 \%$ ethanol series. The seeds were then infiltrated and embedded in Historesin (Leica, Toronto) as the protocol previously described by Yeung (1999). Serial sections, $3 \mu \mathrm{m}$ thick, were cut with glass knives on a Reichert-Jung 2040 Autocut rotary microtome (Reichert-Jung, Vienna, Austria). Histochemical staining of total carbohydrates and protein was performed according to Yeung (1984). The sections were stained with the periodic acid-Schiff procedure for total insoluble carbohydrates, amido black 10B (Merck KGaA, Darmstadt, Germany) for proteins, and counterstained with toluidine blue $\mathrm{O}$ (TBO; Merck KGaA). Red coloration indicated carbohydrates, whereas blue coloration indicated proteins. These preparations were examined and photographed with a light microscope (Axioplan; Carl Zeiss AG, Jena, Germany). Cuticular material can be visualized by stained with $1 \mu \mathrm{g} \cdot \mathrm{mL}^{-1}$ of Nile red (Sigma Chemical Co.). After staining for $10 \mathrm{~min}$, the sections were briefly washed in distilled water and then mounted in water containing $0.1 \%$ n-propyl gallate (Sigma Chemical Co.), an antifading compound (Yeung et al., 1996). The fluorescence pattern was examined and photographed using an epifluorescence microscope (Axioplan) equipped with the Zeiss filter set 15 (546/12-nm excitation filter and 590-nm emission barrier filter).

Culture Medium. In our preliminary experiments, seeds of most Calanthe R. Br. species germinated well on the medium with quarter strength of macroelements of MS basal salts (Murashige and Skoog, 1962). Therefore, in this study, quarter strength of macroelements of MS basal salts with full-strength microelements was used for seed germination. The modified MS medium was supplemented with $20 \mathrm{~g} \cdot \mathrm{L}^{-1}$ sucrose, $100 \mathrm{~mL} \cdot \mathrm{L}^{-1}$ coconut milk, and solidified with $2 \cdot 2 \mathrm{~g} \cdot \mathrm{L}^{-1}$ Phytagel (Sigma Chemical Co.). The $\mathrm{pH}$ was adjusted to 5.7 before autoclaving.

INOCULATION AND CULTURE CONDITIONS. In the germination experiments, each treatment had 20 replicates, which were composed of seeds from five capsules. The capsules were surface-sterilized, in a laminar flow hood, for $30 \mathrm{~min}$ in $1 \%$ sodium hypochlorite solution containing two drops of a wetting agent (Tween 20; ICI Americas Inc., New Castle, Del.) and then rinsed in sterile distilled water. They were then cut open and seeds were scooped and distributed equally onto the surface of the gelled medium in $20 \times 100-\mathrm{mm}$ culture tubes containing $10 \mathrm{~mL}$ of the medium. There were $\approx 100$ seeds per tube. After sowing, the culture tubes were placed in a darkened growth room at $25 \pm 2{ }^{\circ} \mathrm{C}$.

SeEd PRETREatments. For evaluating the effects of different pretreatments, seeds at 210 DAP were collected for the pretreatment experiments. After surface sterilizations, the capsules were dissected and the seeds were scooped out. Both chemical and physical pretreatments used in this study followed previous descriptions (Linden, 1980; Van Waes and Debergh, 1986b). Chemical methods included soaking the seeds in $1 \% \mathrm{NaOCl}$ or $1 \mathrm{~N} \mathrm{NaOH}$, each with two drops of a wetting agent (Tween 20), for $15,30,45$, or $60 \mathrm{~min}$, respectively. In the control, seeds were soaked only in water. For the physical method, seeds were scooped into tubes with distilled water and treated with an ultrasonicator $(200 \mathrm{~W}, 44 \mathrm{kV}, 40 \mathrm{kHz}$, Branson 8210; Branson Ultrasonic Corp., Danbury, Conn.) for 15, 30, 45, or $60 \mathrm{~min}$, respectively. After the pretreatments, the seeds were rinsed three times with sterilized water and then either placed on the germination medium or subjected to the ABA content analysis. The medium used for the germination test was the same as the culture medium mentioned previously. Each pretreatment had 20 replicates, which were composed of seeds from five capsules; in each replicate, there were $\approx 100$ seeds evenly placed on the surface of the medium.

DETECTING THE ENDOGENOUS ABSCISIC ACID CONCENTRATION. The procedure for immunoassays of endogenous ABA concentrations in samples followed the descriptions of Lee et al. (1993). In this investigation, seeds at each developing stage or for different treatments had five replicates. In each replicate, seeds of $0.02 \mathrm{~g}$ were homogenized and pestled in a $1.5-\mathrm{mL}$ Eppendorf tube containing an aqua solution with $80 \%$ methanol and $2 \%$ glacial acetic acid for ABA extraction. For determining ABA concentration of seeds after pretreatments, mature seeds (210 DAP) of $0.02 \mathrm{~g}$ were weighed and scooped into a $1.5-\mathrm{mL}$ Eppendorf tube and then soaked in various aqueous solutions for the seed pretreatments. After the pretreatments, the seeds were rinsed three times with sterilized water and then homogenized for ABA extraction. Extraction was carried out at $4{ }^{\circ} \mathrm{C}$ with continuous shaking for $48 \mathrm{~h}$ in darkness. DL-cis, trans[G- $\left.{ }^{3} \mathrm{H}\right]-\mathrm{ABA}$ (Amersham Biosciences, Buckinghamshire, U.K.) at $166.5 \mathrm{GBq} \cdot \mathrm{mmol}^{-1}$, as an internal standard, was added to the extraction solution $(1.5 \mathrm{~mL})$ at the beginning of extraction for estimating extraction efficiency. Average recovery ranged from $71 \%$ to $76 \%$. Extracts were filtered through filter paper, which were then rinsed twice with extraction solution. The filtrates were dried under vacuum at $30{ }^{\circ} \mathrm{C}$ and then resuspended in $500 \mu \mathrm{L}$ of $100 \%$ methanol. A solution of $0.2 \mathrm{M}\left(\mathrm{NH}_{4}\right)_{2} \mathrm{HPO}_{4}(500 \mu \mathrm{L})$ was subsequently added, and the samples were allowed to stand for $10 \mathrm{~min}$ at $4{ }^{\circ} \mathrm{C}$ until ammonium salts formed. Pigments and phenolics in the ammonium salts solution were removed by passing through a polyvinylpyrrolidone (PVP) column (Mousdale and Knee, 1979). The combined PVP column-filtered solutions were adjusted to $\mathrm{pH} 3.0$ with acetic acid. The acidified solution was eluted through a C-18 cartridge (Whatman, Florham Park, N.J.) to remove polar compounds. ABA trapped in the C-18 cartridge was then eluted with $55 \%$ methanol. The ABA solution was brought to dryness under vacuum at $30{ }^{\circ} \mathrm{C}$. Samples were resuspended in $200 \mu \mathrm{L}$ of Tris-buffered saline 
solution (50 mu Tris $\mathrm{HCl}, 10 \mathrm{~mm} \mathrm{NaCl}, 1 \mathrm{~mm} \mathrm{MgCl}_{2}, 15 \mathrm{~mm}$ $\mathrm{NaN}_{3}, \mathrm{pH}$ 7.5) and stored at $-20{ }^{\circ} \mathrm{C}$ for enzyme-linked immunosorbent assay (ELISA) analysis. Quantification of ABA was obtained by indirect ELISA method according to Walker-Simmons (1987). ABA concentration is expressed as nanograms per milligram of fresh weight.

Germination PERCENTAGE CALCULATION AND STATISTICAL ANALYSIS. Each tube was examined monthly using a Nikon stereomicroscope (10× magnification; Nikon USA, Stamford, Conn.), and germination percentage was scored after $120 \mathrm{~d}$ of culture. Germination was defined as emergence of the embryo from the testa. In all experiments, 20 replicates per treatment were arranged in a completely randomized design. Data were analyzed by using analysis of variance (ANOVA) method followed by Duncan's multiple range test (Duncan, 1955). Data were arsine-transformed before performing ANOVA.

\section{Results}

Changes IN WATER Content. Water content of seeds was $\approx 90 \%$ of fresh weight until 90 DAP (Fig. 1). At this stage, capsules were green and seeds were moist and attached to the placenta. From 120 DAP to 210 DAP, the water content of seeds progressively decreased. The seeds subsequently detached from the placenta at 180 DAP. At 210 DAP, the water content of mature seeds was $\approx 10 \%$.

Timing OF SEED COLlECTION FOR OPTIMAL IN VITRO GERMination. Seeds collected before 90 DAP germinated poorly but thereafter increased to a maximum of $\approx 30 \%$ at 150 DAP (Fig. 2). At 150 DAP, the moist seeds remained attached to the placenta. After 150 DAP, seed germination decreased sharply. During this period, the seeds were creamy white and became dry and free from the placenta, a condition that allowed them to be readily shaken onto the media.

Structural and histochemical STUdy. After fertilization (60 DAP), the zygote was highly polarized with a large vacuole located toward the micropylar end (Fig. 3A). Inside the endosperm cavity, the polar nuclei and one of the male nuclei formed the endosperm complex; these nuclei disintegrated rapidly as the embryo developed. However, an endosperm was finally degenerated in the seed. In the early globular stage

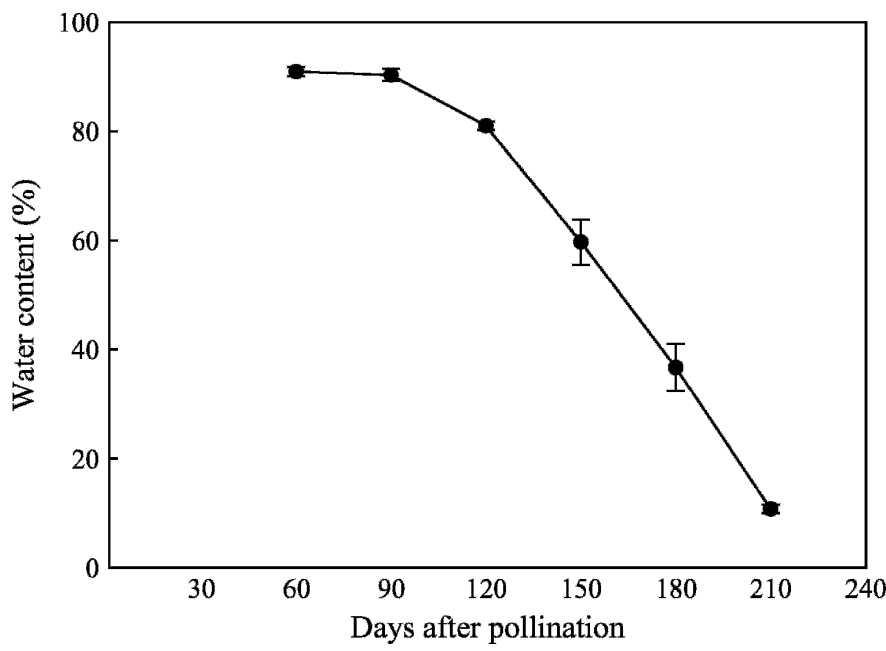

Fig. 1. Changes in water content in developing seeds of Calanthe tricarinata. Error bars represent \pm standard error of three independent experiments including at least 20 replicates each.

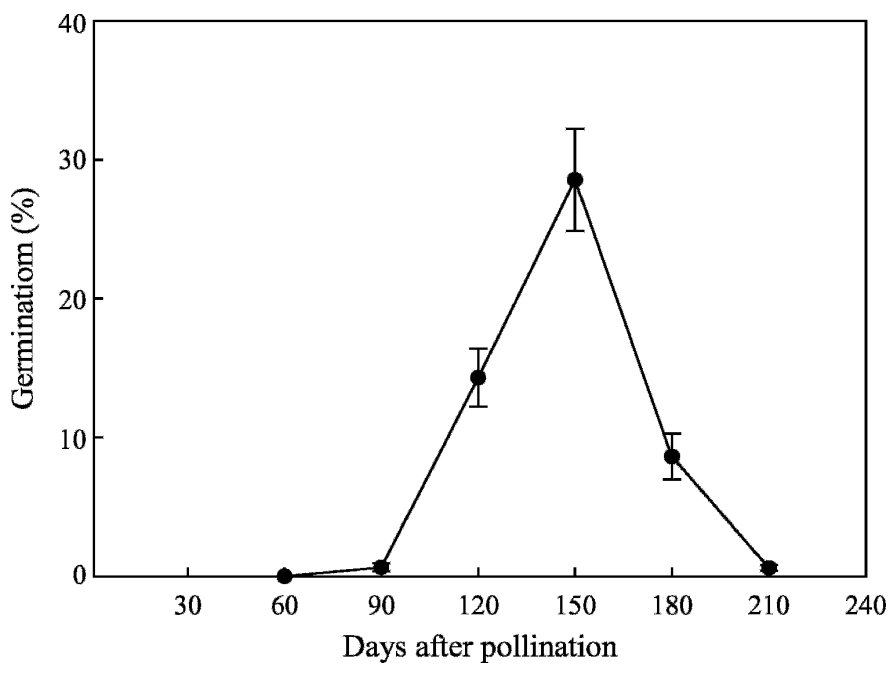

Fig. 2. Changes of the germination percentage in developing seeds of Calanthe tricarinata. Error bars represent \pm standard error of three independent experiments, including at least 20 replicates each. DAP = days after pollination.

(90 DAP), the suspensor cell began to enlarge by the process of vacuolation (Fig. 3B). Within the developing embryo proper, starch granules began to accumulate and tended to congregate around the nucleus of the cell. At 150 DAP, the embryo proper had reached its maximum size (190 $\mu \mathrm{m}$ long, $130 \mu \mathrm{m}$ wide) and mitotic activity seemed to have ceased (Fig. 3C). At the same time, protein and lipid bodies were formed and accumulated within the embryo proper. At $180 \mathrm{DAP}$, the mature embryo filled with storage products that was only six cells long and five to six cells wide (Fig. 3D). Apical meristems and cotyledon were not present. By 210 DAP, desiccation and maturation were completed so that the capsule split from the top end and released the mature seeds. Nile red staining indicated that a thin layer cuticular substance covered the embryo surface and the exposed portion of the suspensor cell (Fig. 3E). After the embryo achieved maturity (180 DAP), the suspensor had degenerated and the cuticular layer had encompassed the embryo (Fig. 3F).

The seedcoat was derived from the outer integument, which was only two cells thick. During early embryo development, the outer integuments were highly vacuolated (Fig. 3B). As the seed matured, a secondary wall was added to the radial and inner tangential walls of the outer layer. At maturity, the cells became dehydrated and compressed into a thin layer (Fig. 3D). Nile red staining indicated the accumulation of cuticular substance on the outer layer of the seedcoat (Fig. 3E, F). Moreover, the dehydrated seedcoat also stained blue green with the TBO staining indicating the presence of phenolic compounds in the walls.

The inner integument was composed of two layers of vacuolated parenchyma cells (Fig. 3B). The cell wall of the inner integument turned a purple color when stained with the TBO stain, suggesting the lack of a secondary wall. The cell wall also reacted negatively to Nile red, indicating the absence of cuticular substance in the walls (Fig. 3E). As the seed matured, the inner integument dehydrated and was compressed into a thin layer, which enveloped the embryo (Fig. 3D).

Changes in abscisic aCID CONCENTRation in DEVeloping SEEDS. At the proembryo stage, the relative lower concentrations of $\mathrm{ABA}$ ( 2.16 to $2.26 \mathrm{ng} \cdot \mathrm{mg}^{-1}$ fresh weight) were observed 

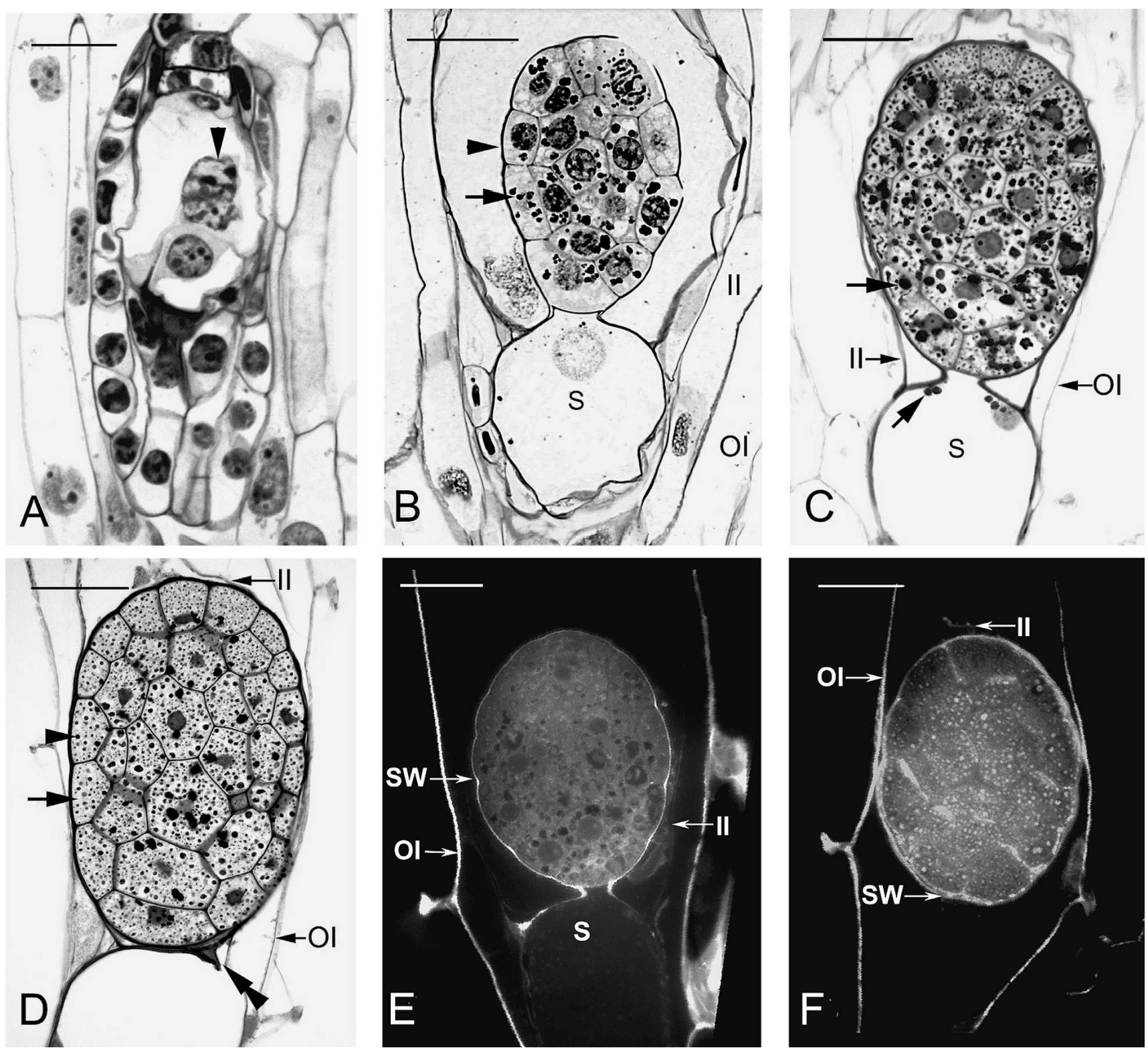

Fig. 3. The histologic study of the embryo development of Calanthe tricarinata. (A) Light micrograph of the zygote just after fertilization at $60 \mathrm{~d}$ after pollination (DAP). The zygote was highly polarized with a chalazally sited nucleus and a vacuole located at the micropylar end. The endosperm complex (arrowhead): the polar nuclei and one of the male nuclei remain free in the cytoplasm. Endosperm failed to develop in this species (scale bar $=10 \mu \mathrm{m})$. (B) At 90 DAP, anticlinal divisions occurring in the outer layer of cells of a globular embryo clearly delineating the protoderm (arrowhead). The suspensor cell (S) enlarged and had a rounded appearance. Starch grains (arrow) within the cells of the embryo proper continued to increase in size in the cells of the embryo proper. II $=$ inner integument, $\mathrm{OI}=$ outer integument $(\mathrm{scale}$ bar $=50 \mu \mathrm{m}) .(\mathrm{C})$ Light micrograph showing a longitudinal section through a globular embryo at $150 \mathrm{DAP}$. At this stage, the embryo proper had reached its maximum size and mitotic activity had stopped, whereas the suspensor had enlarged and elongated toward the micropylar end of the seed. There were starch grains (arrows) scattered within the cells of the embryo proper and the suspensor. The cells were also with an abundant deposition of protein bodies and lipid bodies. The cells of both inner and outer integuments became dehydrated and gradually compressed into a thin layer $(\mathrm{scale}$ bar $=50 \mu \mathrm{m})$. (D) Light micrograph showing a longitudinal section through a mature seed at $180 \mathrm{DAP}$. As the seed approached maturity, there was a simultaneous diminishing in the number of starch granules within the cells. The lipid bodies (arrowhead) and protein bodies (arrow) of various sizes could be found within the cells of the embryo proper. The suspensor had degenerated at this stage; only the vestige (double arrow) could be found (scale bar $=50 \mu \mathrm{m}$ ). (E) Light micrograph showing the fluorescence pattern of a developing seed at 120 DAP after Nile red staining. The outermost layer of outer integument and the surface wall (SW) of the embryo proper reacted positively to the stain. There was a thin layer cuticular substance covered the exposed portion of the suspensor. The inner integument does not fluoresce brightly (scale bar $=50 \mu \mathrm{m})$. $(\mathbf{F})$ Light micrograph showing the fluorescence pattern of a mature seed after Nile red staining. The shriveled inner integument and the outermost layer of outer integument reacted positively to the stain. The $\mathrm{SW}$ of the embryo proper also fluoresced brightly $(\mathrm{scale}$ bar $=50 \mu \mathrm{m})$.

between 60 and 90 DAP. As seeds developed further, ABA concentrations continued to increase (Fig. 4). Maximal ABA concentrations (11.6 ng. $\mathrm{mg}^{-1}$ fresh weight) in seeds were observed at 210 DAP. A majority of the capsules were also split at this time.
EFFECTS OF PRETREATMENTS ON SEED GERMination PERCENTAGE AND ABSCISIC ACID CONCENTRATION OF MATURE SEEDS. The pretreatments of mature seeds with ultrasound, $1 \%$ $\mathrm{NaOCl}$, or $1 \mathrm{~N} \mathrm{NaOH}$ for 15 to 60 min had a marked effect on improving germination percentage and a diminishing of $\mathrm{ABA}$ 


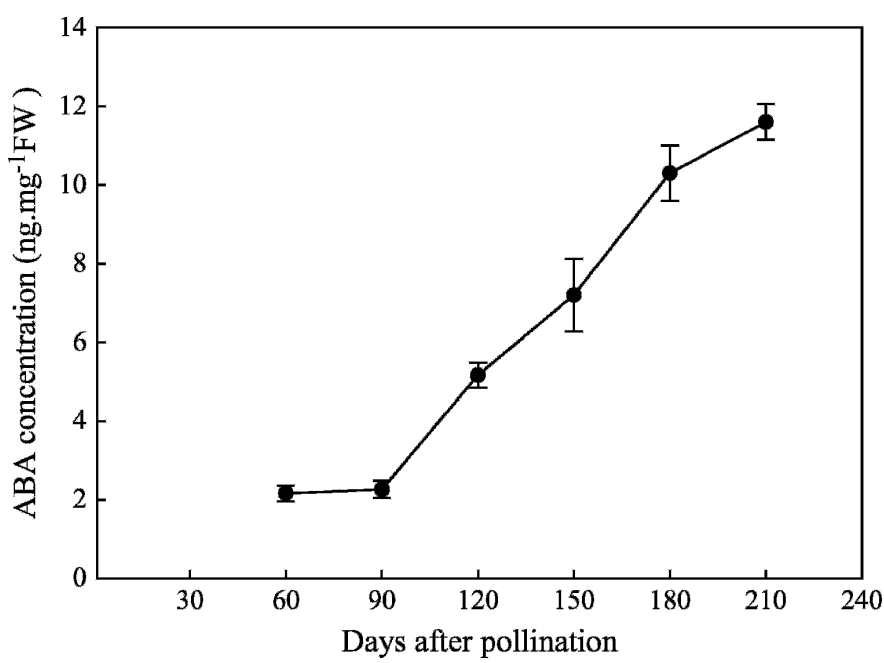

Fig. 4. Changes of abscisic acid concentration in developing seeds of Calanthe tricarinata. Error bars represent \pm standard error of three independent experiments, including at least five replicates each.

concentrations (Table 1). In each pretreatment, there was an optimal duration of treatment that could enhance seed germination. Ultrasonic treatment for $45 \mathrm{~min}$ caused the greatest germination $(34.8 \%)$, but treatment for 60 min reduced germination to $27.1 \%$. Extending the soaking duration of $1 \% \mathrm{NaOCl}$ from 15 to $45 \mathrm{~min}$ enhanced germination percentage from $18.3 \%$ to $32.4 \%$. $\mathrm{NaOCl}$ treatment for $45 \mathrm{~min}$ and $60 \mathrm{~min}$ were equally effective. Soaking seeds with $1 \mathrm{~N} \mathrm{NaOH}$ also resulted in better germination than the control $(20.2 \%$ to $31.8 \%)$. Among the pretreatments, both $1 \mathrm{~N} \mathrm{NaOH}$ and $1 \% \mathrm{NaOCl}$ were more effective for reducing ABA of mature seeds $\left(8.7\right.$ to $1.8 \mathrm{ng} \cdot \mathrm{mg}^{-1}$ fresh weight) than ultrasonic treatments $\left(11.1\right.$ to $6.2 \mathrm{ng} \cdot \mathrm{mg}^{-1}$ fresh weight). The regression analyses revealed highly negative correlations between ABA concentrations and germination percentage for ultrasonic treatment $\left(r^{2}=0.89, \mathrm{y}=-0.1689 \mathrm{x}+\right.$ 12.04) and for $\mathrm{NaOCl}$ treatment $\left(r^{2}=0.88, \mathrm{y}=-0.2559 \mathrm{x}+\right.$ 11.7), whereas such correlation for $\mathrm{NaOH}$ treatment $\left(r^{2}=0.66\right.$, $y=-0.2747 x+11.06$ ) was marginal (Fig. 5).

\section{Discussion}

ABA is known to play an important role in regulating seed embryonic maturation, dormancy, and germination (Bewley and Black, 1985; Koornneef et al., 1989). In Epipactis helleborine (L.) Crants, a hard-to-germinate orchid species, it has been shown that free ABA concentration in mature seeds was 14-fold greater than that in immature seeds (Van der Kinderen, 1987). However, there were no reports of the changes in endogenous ABA concentrations during orchid seed development. In $C$. tricarinata, as the seeds approached maturity, there was a rapid increase in ABA concentration (Fig. 4). In most plant species, ABA concentration is low in developing seeds at the early stage, reaches the highest concentration during middevelopment, and then declines as the seed undergoes maturation (Goldbach and Michael, 1976; Kawakami et al., 1997; King, 1976). However, in developing seeds of C. tricarinata, ABA concentration did not undergo a decline, but continued to increase toward maturity. This observed difference in ABA concentration may relate to the unusual pattern of orchid embryo development (e.g., the lack of endosperm formation and the presence of a thin seedcoat). The tiny seed with a globular-like embryo is one of the distinctive features of the orchid family. The seeds of orchids were attached to the placenta of the capsule; their embryos, with endosperm absent, were housed within a thin seedcoat. This thin seedcoat may not be able to prevent water loss from the developing embryo. The observed increase in ABA concentration may relate directly to the progressive decrease in water content. Additionally, in developing embryos, a negative water potential or water stress could lead to an increase in endogenous ABA (Bray and Beachy, 1985; Robertson et al., 1989; Yeung and Brown, 1982).

Results of this study indicate that the optimal asymbiotic seed germination was obtained at 150 DAP. From the histologic study, the embryo began to mature as it reached its maximum size and storage products were present within the embryo proper at this time. Coincidently, the ABA concentration was relatively low. ABA is an effective inhibitor of germination in immature wheat (Triticum aestivum L.) grain (WalkerSimmons, 1987), cacao (Theobroma cacao L.) embryos (Pence, 1992), and rape (Brassica rapa L.) seed (Finkelstein and Crouch, 1986). In orchids, it has been suggested that high concentrations of ABA occur in seeds that are difficult to germinate such as E. helleborine (Van der Kinderen, 1987). In this study, the combination of maturing embryo and the low concentrations of ABA at 150 DAP likely contributed to the high germination percentage of $C$. tricarinata. It has been known that orchid seeds from immature green capsules can readily germinate for several species. Our success in using the immature orchid seeds as the source for asymbiotic seed germination is most likely the result of the combined effect of embryo maturity and low ABA concentrations. In C. tricarinata, seed germination decreased sharply as the seeds were approaching maturity (150 to 210 DAP) and this

Table 1. Effects of various seed pretreatments on the germination percentage and the endogenous abscisic acid (ABA) concentrations of Calanthe tricarinata mature seeds ${ }^{\mathrm{z}}$.

\begin{tabular}{|c|c|c|c|c|c|c|}
\hline \multirow[b]{2}{*}{ Duration } & \multicolumn{3}{|c|}{ Germination $(\%)$} & \multicolumn{3}{|c|}{$\mathrm{ABA}\left(\mathrm{ng} \cdot \mathrm{mg}^{-1} \mathrm{FW}\right)$} \\
\hline & Ultrasound & $1 \% \mathrm{NaOCl}$ & $1 \mathrm{~N} \mathrm{NaOH}$ & Ultrasound & $1 \% \mathrm{NaOCl}$ & $1 \mathrm{~N} \mathrm{NaOH}$ \\
\hline Control $^{\mathrm{y}}$ & $0.4 \mathrm{~d}^{\mathrm{x}}$ & $0.4 \mathrm{~d}$ & $0.4 \mathrm{~d}$ & $11.6 \mathrm{a}$ & $11.6 \mathrm{a}$ & $11.6 \mathrm{a}$ \\
\hline $15 \min$ & $8.2 \mathrm{c}$ & $18.3 \mathrm{c}$ & $20.2 \mathrm{c}$ & $11.1 \mathrm{a}$ & $8.7 \mathrm{~b}$ & $7.4 \mathrm{~b}$ \\
\hline $45 \mathrm{~min}$ & $34.8 \mathrm{a}$ & $32.4 \mathrm{a}$ & $27.3 \mathrm{bc}$ & $6.6 \mathrm{~b}$ & $2.5 \mathrm{~d}$ & $2.3 \mathrm{~d}$ \\
\hline $60 \mathrm{~min}$ & $27.1 \mathrm{~b}$ & $39.3 \mathrm{a}$ & $21.2 \mathrm{c}$ & $6.2 \mathrm{~b}$ & $2.6 \mathrm{~d}$ & $1.8 \mathrm{~d}$ \\
\hline
\end{tabular}

${ }^{\mathrm{z}}$ The mature seeds were collected at $210 \mathrm{~d}$ after pollination. Germination data were scored after $120 \mathrm{~d}$ of culture.

y In the control, seeds were soaked only in water.

${ }^{x}$ Means within the same column followed by different letters were significantly different at $5 \%$ level by Duncan's multiple range test. 


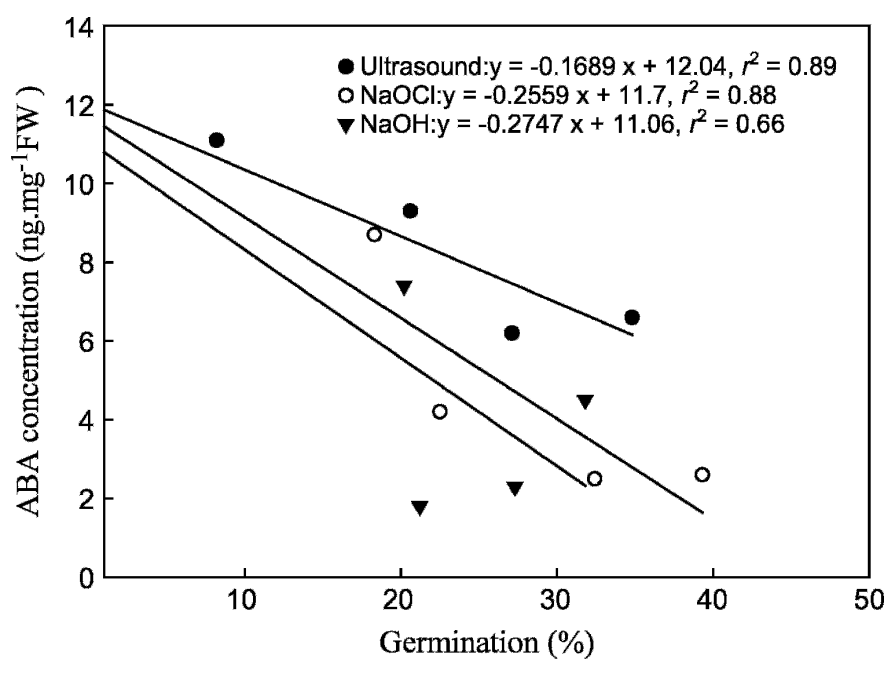

Fig. 5. The correlations between abscisic acid concentrations and germination percentage resulted from different seed pretreatments on Calanthe tricarinata mature seeds collected $210 \mathrm{~d}$ after pollination.

coincided with increasing ABA concentration, decreasing water content, and the accumulation of seed storage products in seed. This observation suggests a regulatory role of ABA in the embryo development of orchid seeds and the prevention of germination at seed maturity.

If $\mathrm{ABA}$ inhibits the seed germination of northern temperate orchids, germination can be promoted by leaching of ABA from the seeds or by preventing ABA accumulation in mature seeds. In our preliminary work, however, the application of the ABA synthesis inhibitor "fluridone" to orchid capsules failed to promote seed germination (data not presented) similar to the study for maize kernels (Fong et al., 1983). In C. tricarinata, it was not easy for the fluridone solution to penetrate the seeds when the solution was just applied to the surface of the developing capsules. For ABA leaching, surface sterilization with $\mathrm{Ca}(\mathrm{OCl})_{2}$ for 2 or $8 \mathrm{~h}$ led to no detectable free $\mathrm{ABA}$ remaining in seeds of Dactylorhiza maculata (L.) Soo (Van Waes and Debergh, 1986a). Accordingly, in this report, we pretreated the mature seeds of $C$. tricarinata with $1 \% \mathrm{NaOCl}$, $1 \mathrm{~N} \mathrm{NaOH}$, or ultrasound to investigate their effects on reducing endogenous ABA and seed germination. With extended duration of each pretreatment, ABA concentrations decreased in seeds (Table 1). The decline of ABA concentration after extended durations of pretreatments correlated negatively with the increase in germination percentage (Fig. 5). However, the extended treatments, i.e., with ultrasound over $45 \mathrm{~min}$ or with $1 \mathrm{~N} \mathrm{NaOH}$ over $30 \mathrm{~min}$, may destroy the seeds and resulted in the decline of germination percentage. The enhancement in germination after these pretreatments may reflect the increase in seedcoat permeability or the reducing of germination inhibitors from the seeds. $\mathrm{NaOCl}$, an oxidizing agent, is commonly used for the purpose of surface-sterilizing seeds and may scratch the rigid seeds (Arditti, 1982; Linden, 1980). As shown in this study, $\mathrm{NaOCl}$ may not only serve the role of scarifying the seedcoat, but also demolish the endogenous ABA. Because ABA is a weak acid, apoplastic ABA preferentially diffuses across the plasma membrane into the more alkaline cytoplasm of mesophyll or epidermis cells (Hartung and Slovik, 1991; Wilkinson and Davies, 1997). According to soaking, seeds with $1 \mathrm{~N} \mathrm{NaOH}$ might shift the $\mathrm{pH}$ toward alkaline and thus facilitate the efflux of ABA from seeds to the soaking solutions.

According to Van Waes and Debergh (1986a), seed germination percentage after pretreatments differed among the orchid species tested. This divergence could be attributed to the varied testa permeability among the species. In contrast to $C$. tricarinata, our previous report on $C$. formosanum showed that seed pretreatment appeared to have little influence on improving germination (Lee et al., 2005). After pretreating with $1 \%$ $\mathrm{NaOCl}$ for $1 \mathrm{~h}$, the mature seeds of $C$. formosanum still floated on the solution, showing their sturdy hydrophobic character. It is interesting to compare the detailed outline of Nile red staining of the seedcoat of the two species. In $C$. tricarinata, only one layer of cells with fluorescence was detected in the outer walls of the seedcoat, whereas both the outer and inner layers of the seedcoat fluoresce strongly in C. formosanum. The additional cuticular substance may make the testa more rigid and resistant to various seed pretreatments.

In conclusion, our results indicate a negative correlation between the concentrations of endogenous ABA and rates of seed germination, which support the supposition that high endogenous ABA concentrations are associated with the poor seed germination (Van der Kinderen, 1987). In addition, we may infer that the effect of these pretreatments on improving germination of mature seeds could be the result of the increased seedcoat permeability or the lowering of ABA in seeds. In the present study, the goal of improving seed germination of the hard-to-germinate species, $C$. tricarinata, was attained. Either collecting the immature seeds at 150 DAP or pretreating the mature seeds could improve asymbiotic seed germination of C. tricarinata.

\section{Literature Cited}

Arditti, J. 1967. Factors affecting the germination of orchid seeds. Bot. Rev. 33:1-97.

Arditti, J. 1982. Orchid biology: Reviews and perspectives, II. Cornell University Press, Ithaca, N.Y.

Bewley, J.D. and M. Black. 1985. Seeds: Physiology of the development and germination. Plenum Press, N.Y.

Bray, E.A. and R.N. Beachy. 1985. Regulation by ABA of $\beta$ conglycinin expression in cultured developing soybean cotyledons. Plant Physiol. 79:746-750.

Chu, C.C. and K.W. Mudge. 1994. Effects of prechilling and liquid suspension culture on seed germination of the yellow lady's slipper orchid (Cypripedium calceolus var. pubescens). Lindleyana 9:153-159.

Duncan, D.B. 1955. Multiple range and multiple F test. Biometrics 11:1-42.

Finkelstein, R.R. and M.L. Crouch. 1986. Rapeseed embryo development in culture on high osmoticum is similar to that in seeds. Plant Physiol. 81:907-912.

Fong, F., J.D. Smith, and D.E. Koehler. 1983. Early events in maize seed development. Plant Physiol. 73:899-901.

Goldbach, H. and G. Michael. 1976. Abscisic acid content of barley grains during ripening as affected by temperature and variety. Crop Sci. 16:797-799.

Hartung, W. and S. Slovik. 1991. Physicochemical properties of plant growth regulators and plant tissues determine their distribution and re-distribution: Stomatal regulation by abscisic acid in leaves. New Phytol. 119:361-382.

Kano, K. 1968. Acceleration of the germination of so-called hard-togerminate orchid seeds. Amer. Orchid Soc. Bul. 37:690-698.

Kawakami, N., Y. Miyake, and K. Noda. 1997. ABA insensitivity and low ABA levels during seed development of non-dormant wheat mutants. J. Expt. Bot. 48:1415-1421. 
King, R.W. 1976. Abscisic acid in developing wheat grains and its relationship to grain growth and maturation. Planta 132:43-51.

Knudson, L. 1922. Nonsymbiotic germination of orchid seeds. Bot. Gaz. 73:1-25.

Koornneef, M., C.J. Hanhart, H.W.M. Hilhorst, and C.M. Karssen. 1989. In vivo inhibition of seed development and reserve protein accumulation in recombinants of abscisic acid biosynthesis and responsiveness mutants in Arabidopsis thaliana. Plant Physiol. 90:463-469.

Lee, Y.I. 2003. Growth periodicity, changes of endogenous abscisic acid during embryogenesis, and in vitro propagation of Cypripedium formosanum Hay. National Taiwan University, Taipei, Taiwan, $\mathrm{PhD}$ Diss.

Lee, T.M., H.S. Lur, and C. Chu. 1993. Role of abscisic acid in chilling tolerance of rice (Oryza sativa L.) seedings. I. Endogenous abscisic acid levels. Plant Cell Environ. 16:481-490.

Lee, Y.I., N. Lee, E.C. Yeung, and M.C. Chung. 2005. Embryo development of Cypripedium formosanum in relation to seed germination in vitro. J. Amer. Soc. Hort. Sci. 130:747-753.

Linden, B. 1980. Aseptic germination of seeds of northern terrestrial orchids. Ann. Bot. Fenn. 17:174-182.

Miyoshi, K. and M. Mii. 1988. Ultrasonic treatment for enhancing seed germination of terrestrial orchid, Calanthe discolor, in asymbiotic culture. Scientia Hort. 35:127-130.

Mousdale, D.M.A. and M. Knee. 1979. Poly-N-vinylpyrrolidone column chromatography of plant hormones with methanol as eluent. J. Chromatogr. 177:398-400.

Murashige, T. and F. Skoog. 1962. A revised medium for rapid growth and bioassays with tobacco tissue cultures. Physiol. Plant. 15:473-479.

Pence, V.C. 1992. Abscisic acid and the maturation of cacao embryos in vitro. Plant Physiol. 98:1391-1395.

Robertson, M., M. Walker-Simmons, D. Munro, and R.D. Hill. 1989. Induction of $\alpha$-amylase inhibitor synthesis in barley embryos and seedlings by abscisic acid and dehydration stress. Plant Physiol. 91:415-420.

Shimura, H. and Y. Koda. 2005. Enhanced symbiotic seed germination of Cypripedium macranthos var. rebunense following inoculation after cold treatment. Physiol. Plant. 123:281-287.

Van der Kinderen, G. 1987. Abscisic acid in terrestrial orchid seeds: A possible impact on their germination. Lindleyana 2:84-87.

Van Waes, J.M. and P.C. Debergh. 1986a. In vitro germination of some western European orchids. Physiol. Plant. 67:253-261.

Van Waes, J.M. and P.C. Debergh. 1986b. Adaption of the tetrazolium method for testing the seed viability and scanning electron microscopy of some western European orchids. Physiol. Plant. 66:435-442.

Veyret, Y. 1969. La structure des semences des orchidaceae et leur aptitude a la germination in vitro en cultures pures. Musee d'Histoire Naturelle de Paris, Travaux du Laboratoire La Jaysinia 3:89-98.

Walker-Simmons, M. 1987. ABA levels and sensitivity in the developing embryos of sprouting and susceptible cultivars. Plant Physiol. 84:61-66.

Wilkinson, S. and W.J. Davies. 1997. Xylem sap pH increase: A drought signal received at the apoplastic face of the guard cell that involves the suppression of saturable abscisic acid uptake by epidermal symplast. Plant Physiol. 113:559-573.

Yeung, E.C. 1984. Histological and histochemical staining procedures, p. 689-697. In: I.K. Vasil (ed.). Cell culture and somatic cell genetics of plants. Vol. 1. Laboratory procedures and their applications. Academic Press, Orlando, Fla.

Yeung, E.C. 1999. The use of histology in the study of plant tissue culture systems - Some practical comments. In Vitro Cell. Dev. Biol. Plant 35:137-143.

Yeung, E.C. and D.C.W. Brown. 1982. The osmotic environment of developing embryos of Phaseolus vulgaris. Z. Pflanzenphysiol. 106:149-156.

Yeung, E.C., S.Y. Zee, and X.L. Ye. 1996. Embryology of Cymbidium sinense: Embryo development. Ann. Bot. (Lond.) 78:105-110. 